\title{
A 25-year retrospective analysis of the American Society of Anesthesiologists physical status classification: did we "up- code" young obese patients when obesity was not yet considered a disease?
}

\section{Vingt-cinq ans de rétrospective sur la classification du statut physique selon l'American Society of Anesthesiologists : avons- nous « gonflé » le codage des jeunes patients obèses alors que l'obésité n'était pas encore considérée comme une maladie?}

\author{
Christopher Guerry, MD, MHS $₫ \cdot$ John F. Butterworth IV, MD \\ Received: 15 March 2017/Revised: 6 January 2018/Accepted: 8 January 2018/Published online: 23 March 2018 \\ (C) Canadian Anesthesiologists' Society 2018
}

\begin{abstract}
Purpose The influence of obesity on anesthetic risk remains controversial, and obesity has only recently been specifically identified as a criterion by which a patient can be given a higher American Society of Anesthesiologistsphysical status (ASA-PS) score. Nevertheless, we hypothesized that clinicians had assigned obese patients a greater ASA-PS score before obesity became an "official" criterion in 2015.

Methods Basic demographic and physical details were collected on patients receiving anesthetics in the Virginia Commonwealth University Health System between 1986 and 2010. The risk ratio (RR) of "up-coding" ASA-PS classification assignments was calculated for patients of varying body mass index (BMI). We specifically focused on the subset of patients aged 20-29 yr in whom the medical sequelae of obesity would not yet likely be manifest.

Results Among a total of 194,698 patients, the percentage who were obese increased from 20\% to $39 \%$ between 1986 and 2010. Obese patients of all ages were more likely than non-obese patients to be classified as ASA-PS II-IV rather than ASA-PS I. The RR and ratio of RR analyses indicated
\end{abstract}

This report was previously presented, in part, at the International Anesthesia Research Society Annual Meeting, San Diego, May 4-7, 2013.

C. Guerry, MD, MHS ( $₫)$. J. F. Butterworth IV, MD Department of Anesthesiology, Virginia Commonwealth University School of Medicine, VCU, P.O. Box 980695, Richmond, VA 23298-0695, USA

e-mail: cguerry@jhsph.edu a consistent pattern of up-coding patients with greater BMI (contingency table Chi-square: $P<0.001$ ). Most notably, relative to patients with a normal BMI, young obese patients aged 20-29 yr had an increased likelihood of upcoding in ASA-PS compared with obese patients in the older cohorts.

Conclusions These findings suggest a consistent and temporally stable practice of up-coding obese patients despite this lack of explicit guidance. The ASA House of Delegates' recent decision to specifically mention obesity reinforces long-existing practices regarding ASA-PS coding and will likely not degrade the validity of data sets collected before the change.

\section{Résumé}

Objectif L'influence de l'obésité sur le risque anesthésique reste controversée. L'obésité n'a été spécifiquement considérée comme un critère permettant d'attribuer un score de statut physique de l'American Society of Anesthesiologists (ASA-PS) plus élevé que récemment. Néanmoins, nous avons formulé l'hypothèse que les cliniciens avaient attribué aux patients obèses un score ASA-PS plus élevé avant même que l'obésité devienne un critère «officiel » en 2015.

Méthodes Des caractéristiques démographiques et des détails physiques de base ont été collectés pour les patients recevant des anesthésiques entre 1986 et 2010 dans le Virginia Commonwealth University Health System. Le rapport de risque $(R R)$ de "surcodage 》 des attributions de classification ASA-PS a été calculé pour des patients ayant divers indices de masse corporelle (IMC). Nous nous 
sommes concentrés sur le sous-groupe des patients âgés de 20 à 29 ans chez lesquels les conséquences médicales de l'obésité ne seraient vraisemblablement pas encore manifestes.

Résultats Sur un total de 194698 patients, le pourcentage d'obèses a augmenté de $20 \%$ à $39 \%$ entre 1986 et 2010.

Les patients obèses de tous âges étaient plus susceptibles d'être classés ASA-PS II à IV plutôt qu'ASA-PS I, par comparaison aux patients non obèses. Les analyses $d u R R$ et $d u$ ratio de $R R$ ont indiqué un profil constant de surcodage des patients ayant un IMC plus élevé (test du chi-2 appliqué au tableau de contingence : $P<0,001)$. Par rapport aux patients ayant un IMC normal, il était particulièrement évident que les jeunes patients obèses (âgés de 20 à 29 ans) étaient plus susceptibles d'avoir un score ASA-PS surélevé par rapport aux patients obèses des groupes d'âge plus élevés.

Conclusions Ces constatations suggèrent une pratique constante et stable dans le temps consistant à surcoder les patients obèses en dépit d'une absence de recommandations explicites. La décision récente de la House of Delegates de l'ASA de mentionner spécifiquement l'obésité renforce ces pratiques déjà anciennes concernant le codage de l'ASA-PS et n'altérera probablement pas la validité de l'ensemble de données collectés avant ce changement.

Coding the "physical status" of patients scheduled for surgery was first proposed by Saklad, Rovenstine, and Taylor in a 1941 committee report to the American Society of Anesthetists, Inc. ${ }^{1}$ Saklad emphasized the importance of substituting the term "physical state" for "operative risk" in a subsequent publication outlining the classifications. ${ }^{2}$ Over the intervening years, the American Society of Anesthesiologists (ASA) physical status (PS) classification system (ASA-PS), as the professional society and classification system came to be known, underwent periodic revisions. The value of the ASA-PS in perioperative risk modelling has been repeatedly shown, and it has found legitimacy in discussions of "operative risk". 3-9 Nevertheless, the ASA-PS continues to suffer from poor inter-observer reliability. Prior studies surveying practitioner ASA-PS rating for hypothetical patients raised concerns that obesity might be associated with inconsistent assignment of ASA-PS scores ${ }^{10-13}$ and that this inconsistency could introduce uncertainty in surgical risk models that incorporate-and are often heavily weighted for-ASA-PS as a risk input. ${ }^{6,14}$ Inconsistent classification could, therefore, degrade the predictive value of ASA-PS in such modelling.
On 15 October 2014, the ASA (through their House of Delegates) expanded the ASA-PS guidelines to include a selection of specific patient descriptions. ${ }^{15}$ Consistent with the widespread belief that obesity is a systemic disease, one that is strongly associated with increased morbidity and mortality, the panel expressly included elevated body mass index (BMI) ranges as criteria for higher ASA-PS classification-i.e., ASA-II for "obese" patients with BMI of $30-40 \mathrm{~kg} \cdot \mathrm{m}^{-2}$ and ASA-III for "morbidly obese" patients with $\mathrm{BMI}>40 \mathrm{~kg} \cdot \mathrm{m}^{-2} \cdot{ }^{16-18}$ If this document led to a substantial change in how clinicians assign ASA-PS scores, data sets collected before the change might no longer be comparable to current data collections. Alternatively, if implicit "up-coding" was already present in the observed time period before the ASA-PS change, then we need not worry whether patients evaluated before the decision of the ASA House of Delegates would have received substantially different ASA-PS scores from those of similar contemporary patients.

Accordingly, we hypothesized that despite the previous lack of specific guidance regarding obesity, clinicians have already "up-coded" these patients. We further hypothesized that there would be a stronger association between obesity and up-coding for younger patients (aged 20-29 yr), in whom there would have been a reduced risk of a diagnosed obesity-associated illness, such as poorly controlled diabetes or hypertension, that would have already met the previously published criteria for an ASAPS > II.

\section{Methods}

The study was reviewed and approved (29 March 2012) under exempt status by the Institutional Review Board of the Virginia Commonwealth University Office of Research Subjects Protection (IRB \# HM14297).

A 25-year data set of 315,053 recorded operative cases across a single hospital system was produced by combining the flat file database (1983 to mid-2002) of a 32-bit Virtual Address Extension system (VAX, Digital Equipment Corporation, Maynard, MA, USA) and the relational database (mid-2004 to 2010) of an Anesthesia Information Management System (AIMS) (Innovian ${ }^{\circledR}$; Drager, Lübeck, Germany). Clinical data were recorded by clinicans during normal conduct of care either on paper for later entry in the VAX database or, after 2003, by direct digital entry into the AIMS database. The 54,995 patients who were either $>89$ or $<18$ yr of age were excluded prior to the analysis, as were the 18,116 who were emergency and/or trauma cases and the 792 patients who had an ASAPS of VI. While 1,478 of the 1,723 (85.8\%) ASA-PS V patients were also coded as emergency or trauma cases and 
Fig. 1 Flow chart of patient selection

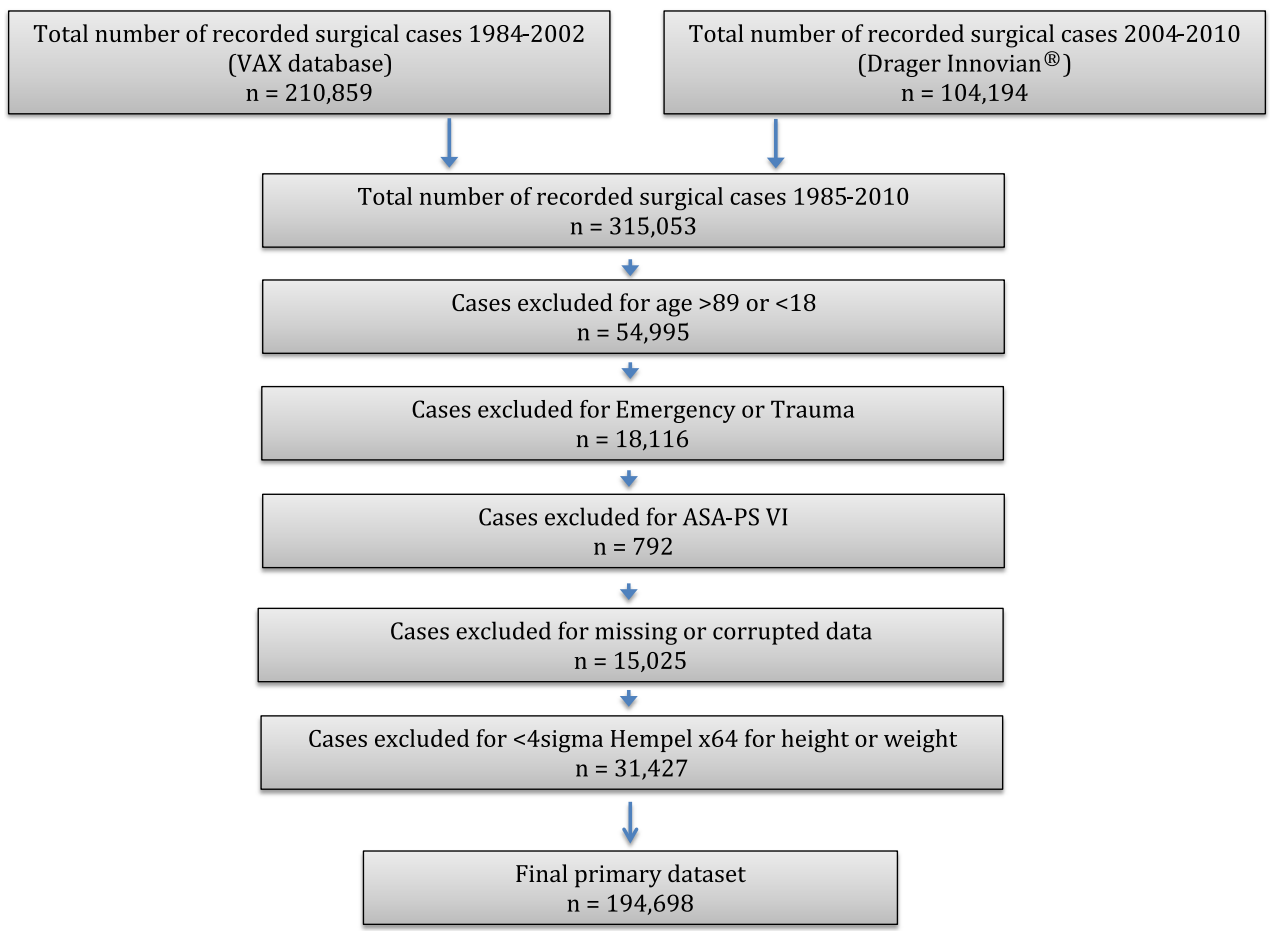

therefore excluded, the 142 who remained in the primary data set were subsequently excluded from certain BMI subanalyses as the determination of a patient as "moribund" and "not expected to survive without the operation" was thought likely to be independent of BMI.

Post hoc data cleansing was then accomplished with logical parsing for errors of data entry (e.g., the categorical error of an ASA of 0 or the quantitative error of anthropomorphic data outside of known human limits) followed by a robust outlier analysis dependent on the median, median absolute deviation, and Hampel X84 rule. ${ }^{9,14}$ A further 46,452 patients were excluded from this combination of logical parsing $(15,025)$ and outlier analysis $(31,427)$. The remaining patient total was 194,698 . Patient selection is outlined in Fig. 1.

The distributions of sex, age, case urgency, and BMI were then determined across ASA-PS classifications. The median with interquartile range [IQR] for BMI in early and late epochs was calculated and the difference between the median BMI evaluated for significance using the Wilcoxon/Kruskal-Wallis rank sum test. Patients were then stratified into BMI-based categories: underweight, healthy (normal), overweight, and obese I-III (Fig. 1). An ordered logistic regression of ASA-PS (I-IV) as an ordinal response fit to $\mathrm{BMI}$ as an ordinal primary predictor variable (BMI-based category) was used to assess the significance of the general association between BMI and ASA-PS classification both with and without additional explanatory variables (e.g., age, gender, and year of surgery). Statistical significance was assessed for the whole model and for all iterations of ASA-PS up-coding (I to II, I to III, I to IV, II to III, II to IV, and III to IV) and all covariates.

The covariate of most interest in the logistic regression model was age, as age is known to be independently associated with the risk of comorbidities and the presence of comorbidities associated with the outcome of interest, ASA-PS. Contingency tables $(r \times c)$ were constructed to explore further the association among ASA-PS I-IV, BMIbased categories, and age. The contingency analysis of ASA-PS by BMI-based categories with blocking by age group was undertaken followed by a Cochran-MantelHaenszel test to assess the independence of BMI (by BMIbased categories) and age (by ten-year age groups).

After characterizing the distributions of BMI and ASAPS, the general association between BMI and ASA-PS, and the potential interaction of age and BMI (with ASA-PS as the response variable), hypothesis testing was then begun. The risk ratio (RR) of up-coding from ASA-PS I to ASAPS II, III, or IV was first calculated for each BMI-based category with the exception of underweight patients (i.e., BMI $<18.5 \mathrm{~kg} \cdot \mathrm{m}^{-2}$ ). These calculations were completed for the entire data set, then, in anticipation of the potentially confounding influence of the comorbid diagnoses that might also lead to higher ASA-PS classification, for the subset of patients between 20 and 29 yr of age, in whom these diagnoses would be less likely. To better quantify the effect of age on these patterns of upcoding, the ratios of the risk ratios (RRR) of up-coding between the two age groups were calculated using the logarithmic transformation described by Altman and 
Bland. ${ }^{19}$ To address the possibility of temporal changes over the 25-year data set, the risk ratios of up-coding in obese patients (combined obese I-III) compared with patients of healthy (normal) weight were calculated for both the 20-89 and the 20-29 yr age groups in two separate epochs: 1985-1989 and 2005-2009. Where there were statistically significant differences between the two epochs, the RRRs with $95 \%$ confidence intervals (CI) were calculated using the Altman and Bland method and the Hutchon calculator. ${ }^{19,20}$

Given the non-normal distributions and ordinal nature of BMI, BMI-based categories, and ASA-PS, non-parametric statistical methods were primarily utilized throughout this study. Nevertheless, further characterization of these nonnormal distributions using classical parametric methods was permitted in certain cases given the larger size of the data set. All parametric and non-parametric analyses were completed using SAS, JMP Pro12.0, and JMP Pro 13.1.0 (SAS Institute, Cary, NC, USA). The calculations for comparing the relative risks were completed initially by hand, then by the Hutchon Calculator for compairing two estimated relative risks. ${ }^{20}$

It should be noted that the number of patients who fell within the BMI range historically described as "normal" (i.e., $18.5-24.9 \mathrm{~kg} \cdot \mathrm{m}^{-2}$ ) comprised only $29 \%$ of the total study population by the 2009-2010 epoch. While there is no consensus yet in the literature on the use of term "normal" in this context, the authors have elected, instead, to describe this BMI range as "healthy" or "healthy (normal)".

\section{Results}

Anesthetic records were reviewed for all 194,698 recorded operative cases between 1 January 1984 and 31 December 2010 that met the selection criteria (Fig. 1). The distributions of sex, age, and ASA-PS classification are presented in Table 1 according to percent contribution to each BMI-based category. The patients had a mean (standard deviation [SD]) age of 48.5 (17.0) yr, and over the 25-year study period, their BMI increased from mean (95\% CI) of 25.5 (25.4 to 25.7$) \mathrm{kg} \cdot \mathrm{m}^{-2}$ in 1985 to 28.5 (28.4 to 28.6$) \mathrm{kg} \cdot \mathrm{m}^{-2}$ in 2010 . The difference in means $(95 \% \mathrm{CI})$ was $3.0(2.8$ to 3.2$) \mathrm{kg} \cdot \mathrm{m}^{-2}(P<0.001)$. In this same time period, the percentage of surgical patients with a healthy (normal) BMI decreased from $42 \%$ to $29 \%$ and the percentage of obese patients rose from $20 \%$ to $39 \%$ (Table 2).

Ordered logistic regression of ASA-PS fit to BMI as either a continuous or categorical variable (i.e., BMI-based category) revealed BMI to have a significant but only moderately predictive contribution to the model. Whole- model statistical significance was maintained (effect likelihood ratio test [Prob $>$ Chi-sq] $<0.001)$ with the introduction of all covariates of interest (age, gender, and surgical year). The statistical significance of parameter estimates was also maintained across all iterations of ASAPS up-coding (I to II, I to III, I to IV, II to III, II to IV, and III to IV) and across all BMI-based categories ([Prob $>$ Chisq] $<0.001)$, with the exception of the BMI category (overweight-normal) term ([Prob $>$ Chi-sq] $<0.62$ ). When logistic regression was repeated and independently stratified by age group, significance was maintained across all iterations of up-coding in each of the age groups with the exception of the 70-79 and 80-89 age groups, in which the patterns of up-coding were inconsistent. In these two groups, whole-model significance was maintained (effect likelihood ratio test [Prob $>$ Chi-sq] $<0.001$ ), but the significance of BMI-based categories was diminshed: in the 70-79 age group BMI category [Obese I-overweight] had a [Prob $>$ Chi-sq] $<0.07$ and BMI category[Obese I-Obese II] had a [Prob $>$ Chi-sq] $<0.11$; in the 80-89 age group all BMI categories lost statistical significance (i.e., [Prob $>$ Chi-sq] $>0.05$ in all categories).

After the completion of the ordered logistic regression analysis, formal hypothesis testing was completed using contingency tables. Compared with patients with a healthy (normal) BMI, the RR of up-coding from ASA-PS-I to ASA-PS $>$ I increased with higher BMI-based categorization (Figs $2 \mathrm{a}$ and $2 \mathrm{~b}$ ). For example, compared with patients of healthy (normal) BMI, the RR (95\% CI) of up-coding from ASA-PS I to ASA-PS III by the categories Obese I, Obese II, and Obese III were 1.17 (1.16 to 1.18), 1.29 (1.27 to 1.30 ), and 1.38 (1.37 to 1.39$)$, respectively, for the patients aged 20-89 (Fig. 2a) and 1.17 (1.06 to 1.29), 1.85 (1.67 to 2.04), and 3.06 (2.90 to 3.23), respectively, for the subgroup of patients aged 20-29 (Fig. 2b). The pattern of increased RR also generally held across increasing iterations of up-coding (i.e., from ASAPS I to ASA-PS II, III, and IV). For example, compared with patients of healthy (normal) BMI, the RRs (95\% CI) of up-coding for Obese II patients from ASA-PS I to ASAPS II, III, and IV were 1.19 (1.18 to 1.20$), 1.29$ (1.27 to 1.30 ), and 1.71 (1.63 to 1.80$)$, respectively, for the patients aged 20-89 (Fig. 2a) and 1.44 (1.40 to 1.48), 1.85 (1.67 to 2.04), and 1.99 (1.37 to 2.89), respectively, for the subgroup of patients aged 20-29 (Fig. 2b). Statistical significance was maintained for each of the three categories of obesity (I to III) with the exception of Obese I up-coding from ASA-PS I to IV in the subset of patients aged 20-29. These patterns of up-coding are best visualized in Figs. $3 \mathrm{a}$ and $3 \mathrm{~b}$, which are mosaic plots of combined contingency analyses, for which differences across all ASA-PS classifications (I through IV) and all 
Table 1 General patient characteristics by BMI classification

\begin{tabular}{|c|c|c|c|c|c|c|}
\hline & \multicolumn{6}{|c|}{ BMI-based category } \\
\hline & Healthy & Overweight & Obese I & Obese II & Obese III & Total \\
\hline Total number of cases & 67,511 & 62,388 & 33,363 & 16,405 & 15,031 & 194,698 \\
\hline Percent by BMI category & $34.7 \%$ & $32.0 \%$ & $17.1 \%$ & $8.4 \%$ & $7.7 \%$ & \\
\hline \multicolumn{7}{|l|}{ Sex } \\
\hline Female & $16.3 \%$ & $14.3 \%$ & $9.7 \%$ & $5.7 \%$ & $6.0 \%$ & $52.0 \%$ \\
\hline Male & $18.4 \%$ & $17.8 \%$ & $7.5 \%$ & $2.7 \%$ & $1.7 \%$ & $48.0 \%$ \\
\hline \multicolumn{7}{|l|}{ Age } \\
\hline $20-29 \mathrm{yr}$ & $5.4 \%$ & $3.4 \%$ & $1.7 \%$ & $0.9 \%$ & $0.9 \%$ & $12.4 \%$ \\
\hline $30-39 \mathrm{yr}$ & $6.0 \%$ & $5.2 \%$ & $2.7 \%$ & $1.6 \%$ & $1.6 \%$ & $17.0 \%$ \\
\hline $40-49 \mathrm{yr}$ & $6.5 \%$ & $6.5 \%$ & $3.8 \%$ & $1.9 \%$ & $2.1 \%$ & $20.9 \%$ \\
\hline $50-59 \mathrm{yr}$ & $6.2 \%$ & $6.8 \%$ & $4.0 \%$ & $2.0 \%$ & $1.8 \%$ & $20.8 \%$ \\
\hline $60-69 \mathrm{yr}$ & $5.4 \%$ & $5.8 \%$ & $3.1 \%$ & $1.4 \%$ & $1.0 \%$ & $16.7 \%$ \\
\hline $70-79 \mathrm{yr}$ & $3.8 \%$ & $3.4 \%$ & $1.5 \%$ & $0.5 \%$ & $0.3 \%$ & $9.5 \%$ \\
\hline $80-89 \mathrm{yr}$ & $1.4 \%$ & $0.9 \%$ & $0.3 \%$ & $0.1 \%$ & $0.0 \%$ & $2.7 \%$ \\
\hline \multicolumn{7}{|l|}{ ASA-PS } \\
\hline ASA-PS I & $4.5 \%$ & $3.6 \%$ & $1.2 \%$ & $0.3 \%$ & $0.1 \%$ & $9.7 \%$ \\
\hline ASA-PS II & $17.1 \%$ & $16.8 \%$ & $9.4 \%$ & $4.7 \%$ & $3.7 \%$ & $51.6 \%$ \\
\hline ASA-PS III & $10.7 \%$ & $9.4 \%$ & $5.5 \%$ & $3.0 \%$ & $3.6 \%$ & $32.2 \%$ \\
\hline ASA-PS IV & $2.3 \%$ & $2.2 \%$ & $1.1 \%$ & $0.4 \%$ & $0.4 \%$ & $6.4 \%$ \\
\hline ASA V & $0.0 \%$ & $0.0 \%$ & $0.0 \%$ & $0.0 \%$ & $0.0 \%$ & $0.1 \%$ \\
\hline
\end{tabular}

ASA-PS = American Society of Anesthesiologists-physical status; BMI = body mass index

BMI-based categories were statistically significant (Contingency Table Chi-square: $P<0.001)$. To address multiple comparisons, a false discovery rate (FDR) was calculated for the contingency table and then repeated with grouping by ten-year age cohorts. The FDR LogWorth was 332.9 for the whole model and ranged from 5.2 to 240.6 for the ten-year age cohorts. An FDR LogWorth $>2.0$ was considered equivalent to a $P<0.01$.

The RRRs of up-coding ASA-PS between the 20-29 yr age group and 20-89 yr age group are presented in Table 3 . The significance of the increased RR of up-coding compared with patients of a healthy BMI (i.e., the increased RRR, as compared with the entire study population) held only in a subset of obese patients (shaded cells in Table 3). Consistent with the logistic regression analysis, the RRR between these two age groups was not statistically significant in overweight patients.

Finally, the assessment of temporal changes in the pattern of up-coding across the data set found no significant difference in the risk ratios of up-coding between the 19851989 and the 2005-2009 epochs in either of the age groups with the exception of up-coding ASA-PS I to III and ASAPS I to IV in the 20-89 yr group (Table 4, grey cells). The RRRs (95\% CI) by epoch were calculated for ASA-PS upcoding I to III [0.93 (0.01 to 0.96)] and ASA-PS I to IV
[1.24 (1.09 to 1.41)]. For all obese patients (Obese I to III ages 20-89 yr) there was a slight decrease in the risk of upcoding from ASA-PS I to III and a slight increase in the risk of up-coding from ASA-PS I to IV over time $(P<0.05)$.

\section{Discussion}

The changing BMI distributions of the patients in our study were consistent with the contemporary epidemic of obesity in western society. ${ }^{21-23}$ Among patients presenting for surgery, we observed a near doubling over the last quarter century of the fraction who were obese. Surgical risk modelling is essential to improving our understanding of the perioperative implications of this epidemic, but this modelling is dependent on the consistent characterization of obesity at the level of clinical practice and data collection. To this end, the ASA has suggested specific guidelines to the ASA-PS classification of obese and morbidly obese patients. The findings in this 25-year data set establish a robust and temporally stable association between increased BMI and increased ASA-PS in the obese patient and suggest that the practice of up-coding of obese patients to a higher ASA-PS was established prior to the recent recommendations by the ASA House of Delegates. 
Table 2 Percentage of patients by BMI-based category

\begin{tabular}{lrr}
\hline BMI category & \multicolumn{2}{c}{ Year } \\
\cline { 2 - 3 } & 1984 & 2010 \\
\hline Underweight & $8.5 \%$ & $2.3 \%$ \\
Healthy (Normal) & $42.0 \%$ & $28.8 \%$ \\
Overweight & $29.8 \%$ & $30.2 \%$ \\
Obese & $19.8 \%$ & $38.7 \%$ \\
Obese I & $11.0 \%$ & $19.3 \%$ \\
Obese II & $4.6 \%$ & $10.4 \%$ \\
Obese III & $4.3 \%$ & $9.0 \%$ \\
\hline
\end{tabular}

$\mathrm{BMI}=$ body mass index

Therefore, these data suggest that patients assessed using contemporary definitions of ASA-PS would likely have been scored similarly in the past, despite the earlier lack of specific guidance from ASA regarding physical status classification and obesity, and long before obesity was considered a disease. ${ }^{15,24-26}$

Also as hypothesized, the association between increased BMI and increased ASA-PS was more pronounced in the younger patients who were least likely to have those potentially confounding obesity-associated systemic comorbidities that would otherwise require higher ASAPS categorization (e.g., type-II diabetes mellitus, hypertension, cardiovascular disease, stroke, and obstructive sleep apnea). While clinicians were significantly more likely to assign ASA-PS II, III, or IV to obese patients than to patients who were not obese, these findings could be partly explained by the presence of these comorbidities. We believe, however, that the strongest evidence that clinicians regarded obesity itself as a comorbidity comes from our finding that a predictable subset of obese patients aged 20-29 yr had a higher RR for up-coding than did patients in the older age groups.

The RRR between these two age groups increased as the BMI-based category increased (from Obese I to Obese III; Table 3). The RRR could only achieve significance if the RR of up-coding of the younger patient group sufficiently exceeded that of the older group. In light of this basic structure, there was a notable lack of significance in the RRR of the higher up-coding categories (ASA-PS I to ASA-PS III or IV; right sided cells of Table 3) and the patients with lower BMI (BMI-based categories; upper cells of Table 3).

There are four likely co-contributory explanations for this lack of significance. First, extremes of up-coding (to ASA-PS III or IV) due to obesity alone were less common overall. Second, extreme up-coding, when due to obesity, was less common in lower BMI-based categories. Third, factors other than obesity were more likely to contribute to extreme up-coding. Lastly, the influence of these other factors was only surpassed by the influence of BMI in the higher BMI-based categories. The hidden factor of greatest influence would most likely be the presence of comorbidities. Furthermore, as comorbidities were not recorded in the available databases, this likely confounding variable could only be indirectly controlled for using age stratification as a surrogate. If, however, the significant RRR truly represented the excess risk of obesity in upcoding, then there would appear to be a dominant pattern of up-coding from ASA-PS I to II for Obese I patients, to II or III for Obese II patients, and to II, III, or IV for Obese III patients (Table 3). A higher degree of confidence in these findings could be made possible by future studies that directly control for the existence of comorbidities.

The strengths of our study lie in the extended time interval, the objectivity of the data, and the large number of patients. There are some limitations, however. The database created for the study had only a limited number of data elements; thus, we could not analyze the relationships among BMI, comorbidities, and perioperative outcomes. The investigation was restricted solely to evaluating patterns of ASA-PS classification. We also recognize that the study was limited to a single site. Our observations may not, therefore, necessarily represent the ASA-PS variability in other institutions. Nevertheless, our data were consistent with prior studies. ${ }^{12,13}$

We also acknowledge that BMI has its limitations as a metric for obesity. While there may be significant associations between BMI and outcomes at the population level, an individual patient's ratio of body fat to lean mass or degree of centripetal adipose distribution (i.e., metrics that more closely associate with metabolic syndrome) may be highly variable within a given BMI category, particularly in the overweight or Obese I populations. ${ }^{27,28}$ Moreover, a recent study has shown that patients with healthy (normal) BMI but central obesity have a greater mortality risk than those with similar BMI but no central obesity. ${ }^{29}$ Furthermore, obesity per se may not be a robust predictor of adverse outcomes. Indeed, a recent study of 5,293 patients has indicated that it is the underweight patient, rather than the obese patient, that has reduced survival after general surgical procedures. ${ }^{30}$ While underweight patients were excluded from the analysis reported here, in light of these recent findings, future studies might include ASA-PS classification patterns in underweight patients and perhaps consider the predictive value of up-coding in this subgroup. Finally, the RRR calculation generally assumes independent sample populations, but the 20-29 yr old cohort is a subgroup of the 20-89 yr old cohort. This particular violation of independence would, however, only lead to an underestimation of the reported effect. 
Fig. 2 (a) Forest plot of risk ratio for up-coding of ASA-PS (ages 20-89 yr). The risk ratio (95\% confidence interval $[\mathrm{CI}]$ ) of up-coding from American Society of Anesthesiologistsphysical status (ASA-PS) I to ASA-PS II, III, or IV is presented by body mass index (BMI)-based category as a forest plot for age group 20-89 yr. Across all iterations of ASAPS up-coding, the risk ratio (relative to healthy weight) increased with increasing BMIbased category. Statistical significance was maintained $(P$ $<0.05)$ across all subgroups.

The marker size is proportional to the patient count. ASA-PS = American Society of

Anesthesiologists-physical status. (b) Forest plot of risk ratio for up-coding of ASA-PS (ages 20-29 yr). The risk ratio (95\% confidence interval $[\mathrm{CI}]$ ) of up-coding from American Society of Anesthesiologistsphysical status (ASA-PS) I to ASA-PS II, III, or IV is presented by body mass index (BMI)-based category as a forest plot for age subgroup 2029 yr. Across all iterations of ASA-PS up-coding, the risk ratio (relative to healthy weight) increased with increasing BMIbased category with the exception of ASA-PS I to III in which the inverse relationship was significant (see $* *$ ).

Statistical significance was maintained $(P<0.05)$ across all subgroups except ASA-PS I to IV in Overweight and Obese I patients $($ see *). ASA-PS = American Society of Anesthesiologists-physical status
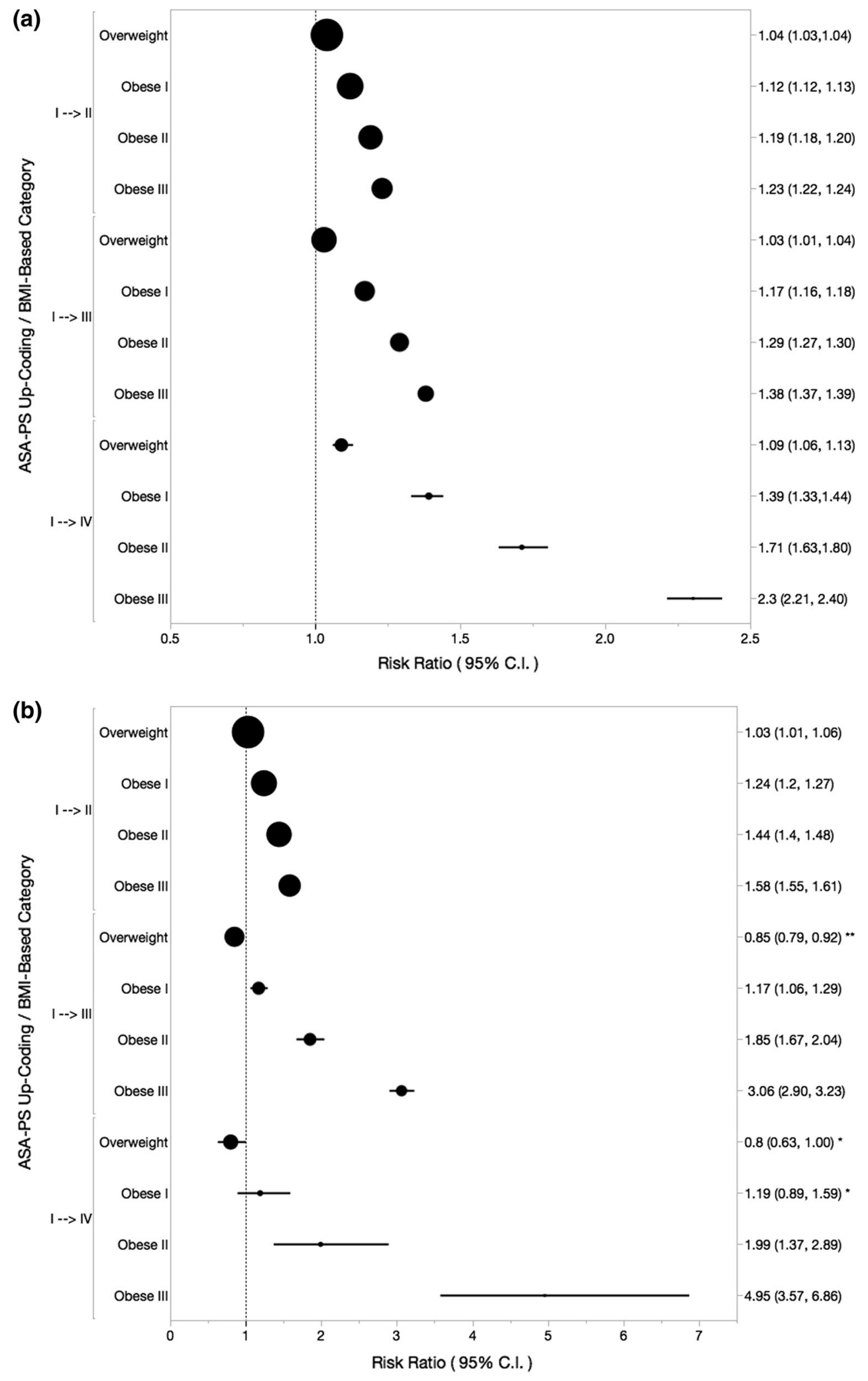

There has been some debate as to whether obesity per se constitutes a disease or specific pathophysiologic derangement worthy of influencing ASA-PS classification. $^{1-5,10,11,31-33}$ Given the increasing evidence that metabolic syndrome (even in early stages) has an influence on perioperative outcomes, we support a minimum classification of ASA-PS II for $\mathrm{BMI}>30$ $\mathrm{kg} \cdot \mathrm{m}^{-2}$ and ASA-PS III for BMI $>40 \mathrm{~kg} \cdot \mathrm{m}^{-2}$, even 

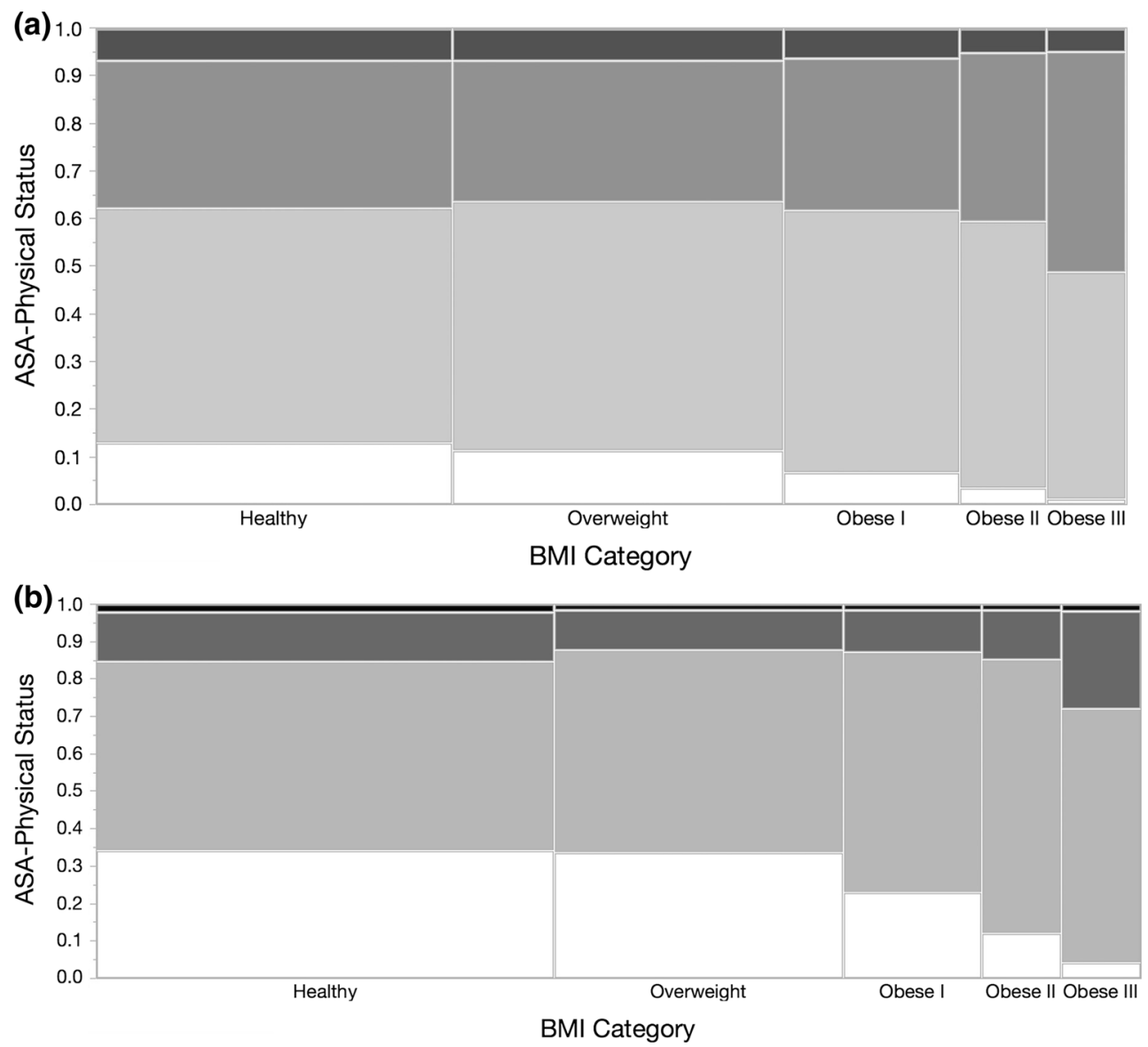

Fig. 3 (a) Contigency analysis-ages 20-89 yr. The contingency analysis characterizes the distribution of American Society of Anesthesiologist (ASA) classification across body mass index (BMI)-based categories. The results are represented here as a mosaic plot. Each BMI-based category is represented by a column, the width of which represents the proportion of the total number of patients that fall into that category. Each of these categories is represented vertically by the proportion of all patients in that category that fall into each of the ASA-PS risk strata. This mosaic plot shows that with increasing BMI there is both a decreasing proportion who

when there is no other diagnosed systemic illness, as per the recent ASA guideline. ${ }^{15,34,35}$ This must, however, be done consistently or we risk degrading the value of ASA-PS in risk prediction. Two modifications that would likely improve the predictive power of the ASA-PS score include replacing the BMI criteria with metrics that better capture the distribution of adipose tissue (e.g., height to weight to waist circumference ratios) and combining the ASA-PS with an assessment of functional status. The value of the latter proposal has been shown in a recent study. ${ }^{36}$

More generally, these data support the ASA House of Delegates commitment to increased ASA-PS specificity in those patient characteristics that are common and that have are ASA I and an increasing proportion who are ASA III. Chi-square: $P<0.001$. ASA-PS $=$ American Society of Anesthesiologistsphysical status. (b) Contingency analysis-ages 20-29 yr. This contingency analysis and corresponding mosaic plot follow the same structure as Fig. 3a, except that this patient subset was restricted to the 24,154 patients ages 20-29. The mosaic plot shows that with increasing body mass index (BMI) there is an even more pronounced effect on both the decrease in the proportion who are ASA I and the increase in the proportion who are ASA III. Chi-square: $P<0.001$. ASA $=$ American Society of Anesthesiologists

Table 3 Ratio of risk ratios for up-coding of ASA-PS comparing 20$29 \mathrm{yr}$ age group with $20-89 \mathrm{yr}$ age group (95\% confidence interval)

\begin{tabular}{|c|c|c|c|}
\hline & ASA-PS I $\geq$ II & ASA-PS I $\geq$ III & ASA-PS I $\geq$ IV \\
\hline Overweight & $\begin{array}{c}0.98 \\
(0.97 \text { to } 1.01)\end{array}$ & $\begin{array}{c}0.82 \\
(0.76 \text { to } 0.89)\end{array}$ & $\begin{array}{c}0.72 \\
(0.58 \text { to } 0.92)\end{array}$ \\
\hline Obese I & $\begin{array}{c}1.11 \\
\text { (1.08 to } 1.14)\end{array}$ & $\begin{array}{c}1.00 \\
(0.90 \text { to } 1.10)\end{array}$ & $\begin{array}{c}0.85 \\
(0.64 \text { to } 1.47)\end{array}$ \\
\hline Obese II & $\begin{array}{c}1.21 \\
(1.18 \text { to } 1.24)\end{array}$ & $\begin{array}{c}1.43 \\
(1.30 \text { to } 1.59)\end{array}$ & $\begin{array}{c}1.16 \\
(0.79 \text { to } 1.70)\end{array}$ \\
\hline Obese III & $\begin{array}{c}1.28 \\
(1.25 \text { to } 1.31)\end{array}$ & $\begin{array}{c}2.15 \\
(2.1 \text { to } 2.34)\end{array}$ & $(1.54$ to 3.00$)$ \\
\hline
\end{tabular}

ASA-PS = American Society of Anesthesiologists-physical status 
Table 4 Risk ratio (relative to normal weight) for up-coding of ASA-PS in obese patients across two epochs

\begin{tabular}{|c|c|c|c|c|c|c|}
\hline & \multicolumn{3}{|c|}{ Ages $20-89$ yr (95\% confidence interval) } & \multicolumn{3}{|c|}{ Ages $20-29$ yr (95\% confidence interval) } \\
\hline & $\begin{array}{c}\text { ASA-PS } \\
\text { I } \geq \text { II }\end{array}$ & $\begin{array}{c}\text { ASA-PS } \\
\text { I } \geq \text { III }\end{array}$ & $\begin{array}{c}\text { ASA-PS } \\
\text { I } \geq \text { IV }\end{array}$ & $\begin{array}{c}\text { ASA-PS } \\
\text { I } \geq \text { II }\end{array}$ & $\begin{array}{c}\text { ASA-PS } \\
\text { I } \geq \text { III }\end{array}$ & $\begin{array}{c}\text { ASA-PS } \\
\text { I } \geq \text { IV }\end{array}$ \\
\hline $\begin{array}{c}\text { Obese I-III } \\
(1985-1989)\end{array}$ & $\begin{array}{c}1.22 \\
(1.20 \text { to } 1.25)\end{array}$ & $\begin{array}{c}1.34 \\
\text { (1.30 to } 1.37)\end{array}$ & $\begin{array}{c}1.6 \\
\text { (1.45 to } 1.77)\end{array}$ & $\begin{array}{c}1.45 \\
(1.36 \text { to } 1.54)\end{array}$ & $\begin{array}{c}2 \\
\text { (1.69 to } 2.36)\end{array}$ & $\begin{array}{c}0.98 \\
(0.42 \text { to } 2.27)\end{array}$ \\
\hline $\begin{array}{c}\text { Obese I-III } \\
(2005-2009)\end{array}$ & $\begin{array}{c}1.18 \\
(1.17 \text { to } 1.20)\end{array}$ & $\begin{array}{c}1.25 \\
\text { (1.24 to } 1.27)\end{array}$ & $\begin{array}{c}1.98 \\
(1.83 \text { to } 2.15)\end{array}$ & $\begin{array}{c}1.48 \\
(1.42 \text { to } 1.54)\end{array}$ & $\begin{array}{c}2.16 \\
\text { (1.93 to } 2.41)\end{array}$ & $\begin{array}{c}2.04 \\
\text { (1.31 to } 3.17)\end{array}$ \\
\hline $\begin{array}{l}\text { Ratio of risk } \\
\text { ratios }\end{array}$ & & $\begin{array}{c}0.93 \\
(0.91 \text { to } 0.96)\end{array}$ & $\begin{array}{c}1.24 \\
(1.09 \text { to } 1.41)\end{array}$ & & & \\
\hline
\end{tabular}

ASA-PS = American Society of Anesthesiologists-physical status

both predictive value in outcomes modelling and poor inter-observer reliability. ${ }^{15,32}$ Consistency in ASA-PS classification is essential for ASA-PS to retain a robust predictive value in perioperative risk modelling. For example, the American College of Surgeons considers ASA-PS an essential variable in the surgical risk calculator developed under the National Surgical Quality Improvement Project, the routine use of which is recommended in the recent American College of Cardiology/American Heart Association Perioperative Clinical Practice Guideline. ${ }^{28}$

Increased objectivity in risk disclosure and informed consent, or improvement in the ability to benchmark in quality improvement initiatives, would require an accurate estimate of perioperative risk. Accordingly, the community of practitioners must score obesity in a consistent way if ASA-PS is to retain its utility in predictive modelling, and, if recent publications are an indication, we may not yet have a consensus on this issue. ${ }^{15,27-29,34,35}$

Conflicts of interest None declared.

Editorial responsibility This submission was handled by Dr. Hilary P. Grocott, Editor-in-Chief, Canadian Journal of Anesthesia.

\begin{abstract}
Author contributions Christopher Guerry helped design the study, conduct the study, analyze the data, and write the manuscript. He has seen the original study data, reviewed the analysis of the data, and approved the final manuscript. John F. Butterworth, IV, helped design the study, conduct the study, and write the manuscript. He has seen the original study data, reviewed the analysis of the data, approved the final manuscript, and is the author responsible for archiving the study files.
\end{abstract}

Funding Departmental funding.

\section{References}

1. Ament R. Origin of the ASA classification. Anesthesiology 1979; 51: 179 .
2. Saklad M. Grading of patients for surgical procedures. Anesthesiology 1941; 2: 281-4.

3. Dripps RD, Lamont A, Eckenhoff JE. The role of anesthesia in surgical mortality. JAMA 1961; 178: 261-6.

4. Owens WD, Felts JA, Spitznagel EL Jr. Tally of ASA classification responses. Anesthesiology 1979; 51: 181.

5. Ranta S, Hynynen M, Tammisto T. A survey of the ASA physical status classification: Significant variation in allocation among Finnish anaesthesiologists. Acta Anaesthesiol Scand 1997; 41: 629-32.

6. Flegal KM, Kit BK, Orpana H, Graubard BI. Association of allcause mortality with overweight and obesity using standard body mass index categories: a systematic review and meta-analysis. JAMA 2013; 309: 71-82.

7. Braz LG, Braz DG, Cruz DS, Fernandes LA, Módolo NS, Braz JR. Mortality in anesthesia: a systematic review. Clinics (Sao Paulo) 2009; 64: 999-1006.

8. Donati A, Ruzzi M, Adrario E, et al. A new and feasible model for predicting operative risk. Br J Anaesth 2004; 93: 393-9.

9. Hampel FR, Ronchetti EM, Rousseeuw PJ, Stahel WA. Robust Statistics: The Approach Based on Influence Functions. John Wiley \& Sons; 1986.

10. Mak PH, Campbell RC. Irwin MG; American Society of Anesthesiologists. The ASA physical status classification: interobserver consistency. Anaesth Intensive Care 2002; 30: 633-40.

11. Owens WD. ASA physical status classifications: a study of consistency of ratings. Anesthesiology 1978; 49: 239-43.

12. Davenport DL, Bowe EA, Henderson WG, Khuri SF, Mentzer $R M$. National Surgical Quality Improvement Program (NSQIP) risk factors can be used to validate American Society of Anesthesiologists physical status classification (ASA-PS) levels. Ann Surg 2006; 243: 636-41; discussion 641-4.

13. Glance LG, Lustik SJ, Hannan EL, et al. The Surgical Mortality Probability Model: derivation and validation of a simple risk prediction rule for noncardiac surgery. Ann Surg 2012; 255: 696702 .

14. Hellerstein JM. Quantitative data cleaning for large databases. United Nations Economic Commission for Europe (UNECE) 2008. Available from URL: http://db.cs.berkeley.edu/jmh/papers/ cleaning-unece.pdf (accessed January 2018).

15. American Society of Anesthesiologists. ASA Physical Status Classification System. Available from URL: https://www.asahq. org/resources/clinical-information/asa-physical-statusclassification-system (accessed January 2018). 
16. Calle EE, Thun MJ, Petrelli JM, Rodriguez, C, Heath CW Jr. Body-mass index and mortality in a prospective cohort of U.S. adults. N Engl J Med 1999; 341: 1097-105.

17. Stevens J, Jianwen C, Pamuk ER, Williamson DF, Thun MJ, Wood JL. The effect of age on the association between body-mass index and mortality. N Engl J Med 1998; 338: 1-7.

18. World Health Organization. Physical status: the use and interpretation of anthropometry. Report of a WHO Expert Committee. Available from URL: http://apps.who.int/iris/bitstream/10665/37003/1/WHO_ TRS_854.pdf (accessed January 2018).

19. Altman DG, Bland JM. Interaction revisited: the difference between two estimates. BMJ 2003; 326: 219.

20. Hutchon DJ. Calculations for comparing two estimated relative risks (online calculator). Available from URL: http://www. hutchon.net/CompareRR.htm (accessed January 2018).

21. Finucane MM, Stevens GA, Cowan MJ, et al. National, regional, and global trends in body-mass index since 1980: systematic analysis of health examination surveys and epidemiological studies with 960 country-years and $9 \cdot 1$ million participants. Lancet 2011; 377: 557-67.

22. Flegal KM, Troiano RP. Changes in the distribution of body mass index of adults and children in the US population. Int $\mathrm{J}$ Obes Relat Metab Disord 2000; 24: 807-18.

23. Penman AD, Johnson WD. The changing shape of the body mass index distribution curve in the population: implications for public health policy to reduce the prevalence of adult obesity. Prev Chronic Dis 2006; 3: A74.

24. Field AE, Coakley EH, Must A, et al. Impact of overweight on the risk of developing common chronic diseases during a 10-year period. Arch Intern Med 2001; 161: 1581-6.

25. Alexander JK. Obesity and coronary heart disease. Am J Med Sci 2001; 321: 215-24.

26. Klein S, Burke LE, Bray GA, et al. Clinical implications of obesity with specific focus on cardiovascular disease: a statement for professionals from the American Heart Association Council on Nutrition, Physical Activity, and Metabolism: endorsed by the American College of Cardiology Foundation. Circulation 2004; 110: 2952-67.

27. Guh DP, Zhang W, Bansback N, Amarsi Z, Birmingham CL, Anis $A H$. The incidence of co-morbidities related to obesity and overweight: a systematic review and meta-analysis. BMC Public Health 2009; 9: 88.

28. Cheah MH, Kam PC. Obesity: basic science and medical aspects relevant to anaesthetists. Anaesthesia 2005; 60: 1009-21.

29. Sahakyan KR, Somers VK, Rodriguez-Escudero JP, et al. Normal-weight central obesity: implications for total and cardiovascular mortality. Ann Int Med 2015; 163: 827-35.

30. Tjeertes EK, Hoeks SE, Beks SB, et al. Obesity - a risk factor for postoperative complications in general surgery? BMC Anesthesiol 2015; 15: 112.

31. Barbeito A, Muir HA, Gan TJ, et al. Use of a modifier reduces inconsistency in the American Society of Anesthesiologists physical status classification in parturients. Anesth Analg 2006; 102: 1231-3.

32. Keats AS. The ASA classification of physical status-a recapitulation. Anesthesiology 1978; 49: 233-5.

33. Sidi A, Lobato EB, Cohen JA. The American Society of Anesthesiologists' physical status: category V revisited. J Clin Anesth 2000; 12: 328-34.

34. Vacanti CJ, VanHouten RJ, Hill RC. A statistical analysis of the relationship of physical status to postoperative mortality in 68,388 cases. Anesth Analg 1970; 49: 564-6.

35. Wolters $U$, Wolf $T$, Stützer $H$, Schröder T. ASA classification and perioperative variables as predictors of postoperative outcome. $\mathrm{Br}$ J Anaesth 1996; 77: 217-22.

36. Visnejevac $O$, Davari-Farid $S$, Lee $J$, et al. The effect of adding functional classification to ASA status for predicting 30-day mortality. Anesth Analg 2015; 121: 110-6. 